\title{
Prevalence of Diarrhea in Summer Season in the Coldest Valley of Kalam Swat
}

\author{
Imran Uddin ${ }^{1 *}$ and Muhammad Younas ${ }^{2}$ \\ 1(Post RN, BScN, RN, BA (Sociology) Charge Nurse in Civil Hospital Kalam Swat, Pakistan \\ ${ }^{2}(\mathrm{MScN}, \mathrm{BScN}, \mathrm{BSc})$ Clinical Nurse Manager, Shaukat Khanum Memorial Cancer Hospital, \\ Pakistan
}

*Corresponding author: Imran Uddin (Post RN BScN, RN, BA (Sociology), Civil hospital Kalam Swat, Pakistan, Email: imranuddinusn@gmail.com

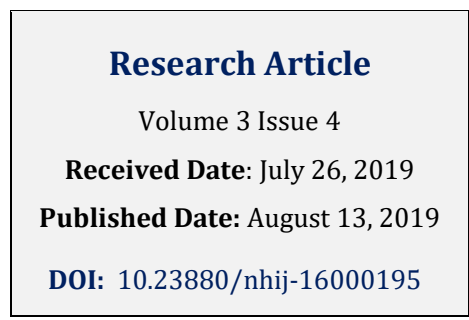

\begin{abstract}
Introduction: Diarrhea is one of the leading causes of death in developing countries and its prevalence is very high in rural areas like in the valley of Kalam district, Swat, because there is no system of chlorination and purification of drinking water.
\end{abstract}

Objective: The objective of the study was to estimate the prevalence of diarrhea in the valley of Kalam Swat in summer season of 2017.

Methods: A descriptive cross sectional study was conducted over a period of six months in government civil hospital of tehsil Kalam Swat. The statistics of frequency of age wise and gender wise distribution of diarrhea were calculated. Tables, bar charts and plotted charts were used to present the data.

Results: Total 2057 cases of diarrhea were identified in the six months duration of the study. The total number of males with the diarrhea disease were 1226 (59.6\%), whereas, total females with diarrhea were 831(40.3\%). In addition, the total numbers of diarrheal cases less than 5 years were 767, and that of more than five years were 1290.

Conclusion: The prevalence and percentage of diarrhea in the coldest valley of Kalam Swat was much high as compared to other big cities of the country.

Keywords: Diarrhea; Seasonal variation; Age distribution; Gender distribution; Kalam valley; Swat; Pakistan

\section{Introduction}

Diarrhea is a disease in which the patient has three or more than three loose stools in a day [1]. It is one of the leading causes of deaths in underdeveloped countries. According to an estimate 165 million people suffers from shigellosis worldwide and $99 \%$ cases occur in developing countries, $69 \%$ victims are children in the age group of 1 5 years [2]. It is a general assumption by many, that diarrhea is related to consumption of contaminated water, food and would mostly occur in hot areas. However, a lot of patients were observed presenting with frequency of loose stool in civil hospital of tehsil Kalam Swat.

Kalam valley is the coldest valley in the province of Khyber Pakhtunkhwa of Pakistan. It is famous for its natural beauty and therefore remains a popular spot for tourists. In addition, as per the local residents the food and water here are considered pure and free from any sort of contamination. 


\section{Nursing \& Healthcare International Journal}

Diarrhea remains the leading cause of morbidity and mortality in children under 5 years of age worldwide [3]. The burden is disproportionately high among children in low- and middle-income countries and is very fatal in the young age and may cause death if not treated properly. Although, how fatal disease diarrhea is, but unfortunately, there is no data available on the prevalence of diarrhea in Kalam valley because no such research has been done. The magnitude of diarrheal cases is high enough in the valley in summer season. This study was planned to find out the prevalence of diarrhea in summer session in the valley of Kalam Swat.

\section{Aim of the Study}

The aim of the study was to "estimate the prevalence of diarrhea cases in the valley of Kalam Swat in summer season of 2017".

\section{Methodology}

\section{A Descriptive Cross-Sectional Study was Employed}

This descriptive cross sectional study was conducted in government civil hospital of tehsil Kalam Swat. The data was collected using the hospital records of patients from 1st March 2017 to 31th August 2017. The duration of six months was taken because the weather in these months is a little warmer and is consider as summer. In addition, the population also gets increase in this season because the residents as well as many tourists visit the valley. The study participants were all the OPD and emergency patients.

Microsoft excel 2013 was used to analyze the data. The two variables taken were, gender wise prevalence of diarrhea and age wise prevalence of diarrhea. The age wise distribution was taken as having diarrhea for less than five years and more than five years. The statistics of frequency of distribution of diarrhea in age wise as well gender wise were obtained. Moreover, the percentages of diarrhea patients in the separate months were obtained.
The tables, bar charts and plotted charts are used to represent the data.

\section{Ethical Consideration}

Written permission was obtained from in charge of the government civil hospital Kalam Swat.

\section{Results}

The total admissions in the six months duration from March 01 to July 31, 2017 were 21,523. These admissions included the daily OPD patients and emergency patients. The diarrheal cases among these admissions were 2,057 as shown in the Table 1 . The month wise prevalence of diarrheal cases was 67 in March, 153 in April, 316 in May, 562 in June, 564 in July and 395 in August respectively. The bar graph in figure-2 shows the month wise prevalence of diarrhea. The gender wise prevalence of diarrhea among total cases of diarrhea was 1,226 male patients and 831 female patients. In addition, the age wise prevalence of diarrheal cases was 767 less than 5 years patients and 1,290 more than five years patients. The peak incident of diarrhea was in the months of June and July, which were 562 and 564 respectively, as illustrated in the graph chart in Figure 1.

The age wise prevalence of diarrhea in separated months is delineated in Figure 2. The month wise total cases of diarrhea less than five years were $26,63,119$, 246, and 204, 109 respectively. Whereas, the month wise cases of diarrhea more than five years were 41, 90, 197, 316,360 and 286 respectively as shown in Table 1 . The gender wise prevalence of diarrhea of male patients in the months of March, April, May, June, July and August were $35,97,177,341,326$, and 250 respectively. Among the female patients, the prevalence in these months was 32 , 56, 139, 221, 238 and 145 respectively as shown in Figure 3 . By looking to the percentage of diarrhea in different months of summer, it becomes clear from Table 2 that it was increased in the months of June and July that were $13.6 \%$ and $10.9 \%$ respectively.

\begin{tabular}{|c|c|c|c|c|c|c|c|}
\hline Month & $\begin{array}{c}\text { Total } \\
\text { admission }\end{array}$ & $\begin{array}{c}\text { Diarrhea } \\
\text { cases }\end{array}$ & $\begin{array}{c}\text { Male } \\
\text { patients }\end{array}$ & $\begin{array}{c}\text { Female } \\
\text { patients }\end{array}$ & $\begin{array}{c}<\mathbf{5} \\
\text { years }\end{array}$ & $\begin{array}{c}>\mathbf{5} \\
\text { years }\end{array}$ & $\begin{array}{c}\text { Other } \\
\text { cases }\end{array}$ \\
\hline March & 1711 & 67 & 35 & 32 & 26 & 41 & 1644 \\
\hline April & 2154 & 153 & 97 & 56 & 63 & 90 & 2001 \\
\hline May & 4307 & 316 & 177 & 139 & 119 & 197 & 3991 \\
\hline June & 4127 & 562 & 341 & 221 & 246 & 316 & 3565 \\
\hline July & 5136 & 564 & 326 & 238 & 204 & 360 & 4572 \\
\hline August & 4088 & 395 & 250 & 145 & 109 & 286 & 3693 \\
\hline Grand Total & 21523 & 2057 & 1226 & 831 & 767 & 1290 & 19466 \\
\hline
\end{tabular}

Table 1: The diarrheal cases. 


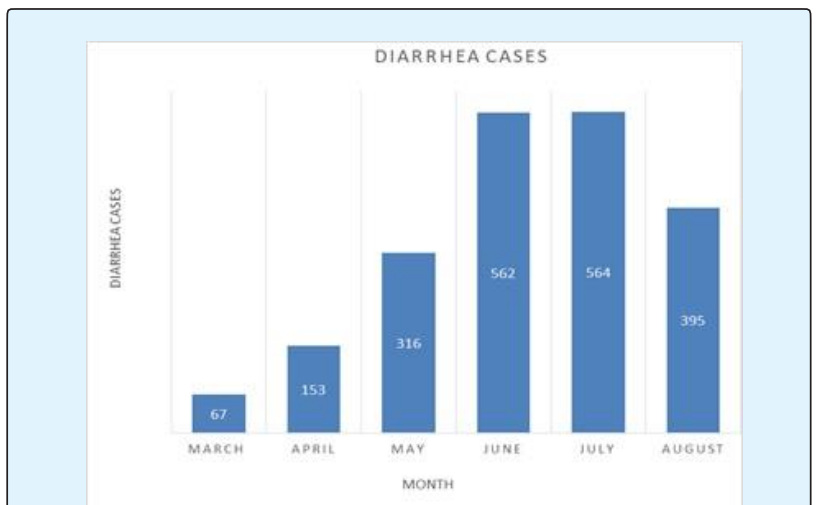

Figure 1: The peak incident of diarrhea.

\begin{tabular}{|c|c|c|c|c|c|c|}
\hline Month & Diarrhoea \% & $\begin{array}{c}\text { \% of males with } \\
\text { Diarrhoea }\end{array}$ & $\begin{array}{c}\text { \% of females with } \\
\text { Diarrhoea }\end{array}$ & $<\mathbf{5}$ years \% & $\mathbf{> 5}$ years \% & $\begin{array}{c}\text { 0ther } \\
\text { cases \% }\end{array}$ \\
\hline March & 3.91583869 & 52.23880597 & 47.76119403 & 38.80597015 & 61.19403 & 96.08416 \\
\hline April & 7.10306407 & 63.39869281 & 36.60130719 & 41.17647059 & 58.82353 & 92.89694 \\
\hline May & 7.33689343 & 56.01265823 & 43.98734177 & 37.65822785 & 62.34177 & 92.66311 \\
\hline June & 13.6176399 & 60.67615658 & 39.32384342 & 43.77224199 & 56.22776 & 86.38236 \\
\hline July & 10.9813084 & 57.80141844 & 42.19858156 & 36.17021277 & 63.82979 & 89.01869 \\
\hline August & 9.66242661 & 63.29113924 & 36.70886076 & 27.59493671 & 72.40506 & 90.33757 \\
\hline
\end{tabular}

Table 2: The percentage of diarrhea in different months of summer.

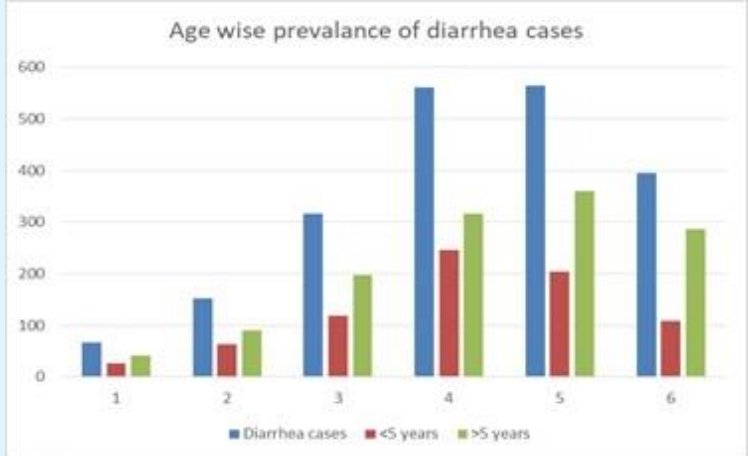

Figure 2: The age wise prevalence of diarrhea in separated months is delineated.

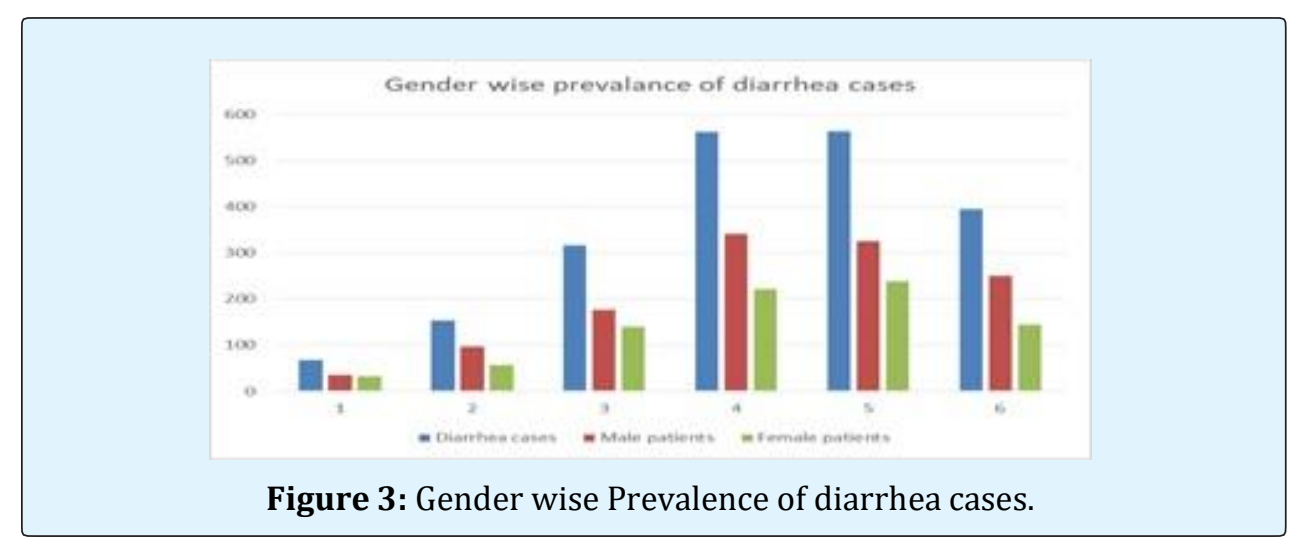




\section{Nursing \& Healthcare International Journal}

\section{Discussion}

As the previous researches also show that diarrhea is very prevalent in different regions of Pakistan. Beside this, it is more common in urban and sub urban areas. Diarrheal diseases are frequent in Pakistan claiming about 118,000 lives each year, most of which are children $<5$ years living in rural communities. In addition, it was often observed that adult urban and suburban dwellers also face diarrheal episodes [4]. The findings of this study also showed that the proportion of diarrhea was high enough in the region. There were total of 2,057 cases of diarrhea among 21,523 admitted patients. The percentage of diarrhea was round about $10 \%(9.55 \%)$, which is high enough because the population of Kalam is not as large as other big cities of Pakistan.

The findings of a study across Pakistan showed that in a duration of two years, the total numbers of patients with acute watery diarrhea from April 2006 to May 2008 were: 23,212 in LCH (Lahore), 2,028 in RGH (Rawalpindi), 937 in MHPMC (Peshawar), 2,417 in NICH (Karachi) and 1,991 in KGH (Karachi) [5]. In comparison to the above study, the results of our study are alarmingly high, because this data was collected in six months duration and valley Kalam is a comparatively small region as compared to the mentioned big cities of Pakistan.
The total males with the diarrhea disease were 1226 (59.6\%), and the total females with the diarrhea disease were $831(40.3 \%)$ as shown in Table 1 . This significant difference may be due to the consumption of street food by males in hotels and bazars. This particular is in line with the findings of a study in Pakistan where, there was significant difference in pin point prevalence of diarrhea males $(10.4 \%)$ were more prone to diarrhea than that of females (8.1\%) [6]. The same finding is also confirmed by another study, that rotavirus is the single most common cause of acute watery diarrhea worldwide and studies have shown that rotavirus affect male gender more than female [7].

In addition, the weather has also great impact on the health of the population. It was also found out that the ratio of diarrhea was increased in hot weathers (Figure 4). The weather in August and after words becomes colder in the valley, so the incidents of diarrhea also get decrease. The occurrence of infectious disease in hot weather is due to a number of reasons. In hot and humid weather, the growth of pathogenic organisms in the food and other material get increased, also summer is the breeding season for flies that act as mechanical vectors carrying enter pathogens to food and water [6]. Moreover, the prevalence of diarrhea in summer season was high, that was $42.6 \%[2,6,8]$.

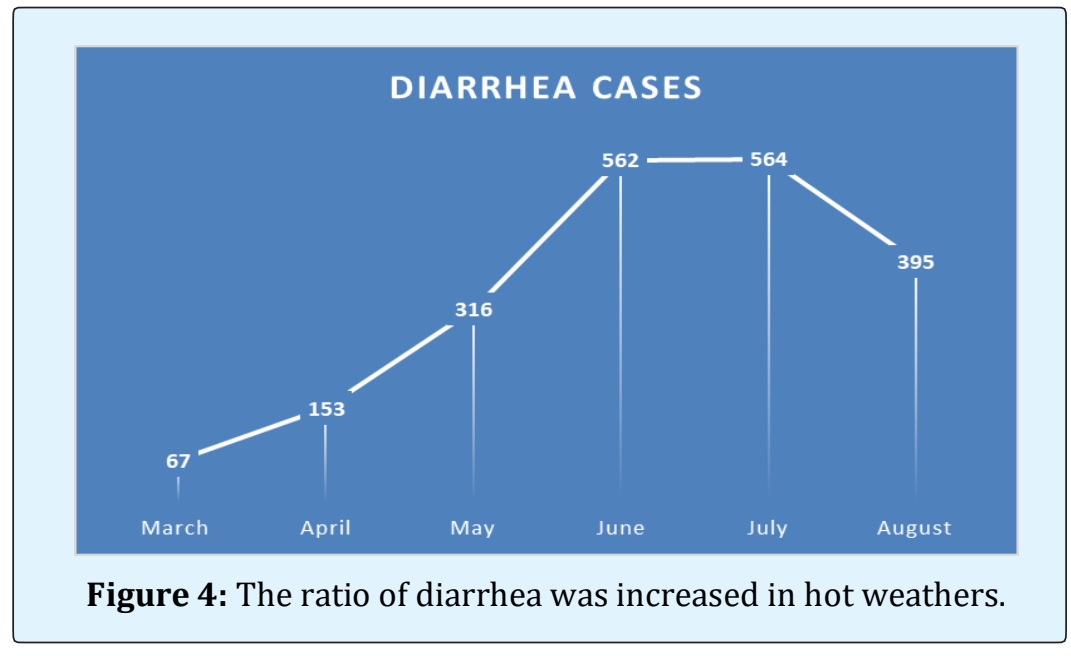

In addition, the hygienic condition of rural communities is not good which also adds to the outbreak of the infectious diseases. The drinking water resources in rural areas are mainly contaminated by animal wastes, garbage, low improvement index of bathroom and toilet, pipe breakage due to corrosion and long track, agricultural activities, lack of personal and food hygiene, the lack of regular and continuous chlorination and lack of water treatment facilities [9]. Our study's findings are in corroboration with the above mentioned study as Kalam valley is also a rural area where most of the drinking water resources such as water tanks and springs are contaminated by above mentioned impurities when there is heavy rain fall. Through rain water these contaminants get mixed with the drinking water, which ultimately leads to spread of infectious diseases like diarrhea. Approximately $44 \%$ of Pakistani communities have no access to safe drinking water and the situation is far 


\section{Nursing \& Healthcare International Journal}

worse in rural areas $90 \%$ of the population is deprived of safe drinking water [10]. This clearly indicates that drinking water in rural areas cannot be considered safe.

\section{Limitations of the Study}

The main limitation of the study is that data was collected from one hospital only. Although, this civil hospital is the biggest in the region, still majority of the people visits other centers as well. So, if the data was collected from all health centers of the region, the results would be more fruitful.

\section{Conclusion}

In conclusion, based on the study findings it can be stated that infectious diseases like diarrhea is not confined to hot and populated regions only. The study results clearly showed that the prevalence of diarrhea is much high in the region as compared to the other big cities of the country. There were total 2,057 cases of diarrhea cases identified in only one hospital of the region.

\section{Recommendations}

It is suggested that the government should give proper attention to this issue. Moreover, efforts should be made to improve the sanitation system of the residential areas of Kalam valley. Provision of safe drinking water has to be made sure for people of the region. For this purpose, water purification plants should be installed. Further research studies should be carried out on larger scales to identify the burden of different water borne diseases.

\section{Acknowledgment}

We acknowledge the support and cooperation of Dr. Masood (incharge of the civil hospital Kalam Swat) and Ms. Yasmeen Parpio (our respected teacher).

\section{References}

1. Maheshwary N, Noor S, Nawaz H, Wajid Z, Qaiser F, et al. (2017) Awareness of Mothers about Diarrhea; A Cross Sectional Comparative Study Focusing on Consciousness of Diarrhea among Different Socioeconomic Classes in Pakistan. International Journal of Pediatrics \& Child Care 2(1): 1-6.
2. Mengistie B, Berhane Y, Worku A (2013) Prevalence of diarrhea and associated risk factors among children under-five years of age in Eastern Ethiopia: A cross-sectional study. Open Journal of Preventive Medicine 3(7): 446-453.

3. Akhtar U, Syed NM, Malik IA, Naqvi MH, Bhatti JA (2012) Bacterial Pathogens Causing Severe Acute Watery Diarrhea During a Summer Month in a Tertiary Care Setting, Islamabad. Pakistan Journal of Medical Research 51(3): 104-107.

4. Kazi AM, Warraich GJ, Qureshi S, Qureshi H, Khan MMA, et al. (2014) Sentinel hospital-based surveillance for assessment of burden of rotavirus gastroenteritis in children in Pakistan. PloS one 9(10): e108221.

5. Ahmed SF, Farheen A, Muzaffar A, Mattoo GM (2010) Prevalence of Diarrhoeal Disease, its Seasonal and Age Variation in under-fives in Kashmir, India. Int J Health Sci (Qassim) 2(2): 126-133.

6. Khattak TA, Ali S, Safdar CA, Aslam MS (2011) Frequency of rotavirus infection in children with acute diarrhea. Pakistan Armed Forces Medical Journal 61(1): 1-6.

7. Nisar M, Ahmed M, Mushtaq MH, Khan SA, Hussain A, et al. (2014) Clinico-epidemiology of shigellosis in children suffering from Diarrhea in District Lahore, Pakistan. Int J Curr Microbiol App Sci 3(2): 950-957.

8. Musengimana G, Mukinda FK, Machekano R, Mahomed H (2016) Temperature variability and occurrence of diarrhoea in children under fiveyearsold in Cape Town metropolitan sub-districts. International journal of environmental research and public health 13(9): 859.

9. Pirsaheb M, Sharafi K, Ahmadi E, Moradi M (2017) Prevalence of the waterborne diseases (diarrhea, dysentery, typhoid, and hepatitis A) in West of Iran during 5 years (2006-2010). Annals of Tropical Medicine and Public Health 10(6): 1524-1528.

10. Qasim M, Anees MM, Bashir A (2014) Unhygienic water is the cause of water borne disease among villagers: A case of Gujrat-Pakistan. World Applied Sciences Journal 29(12): 1484-1491. 